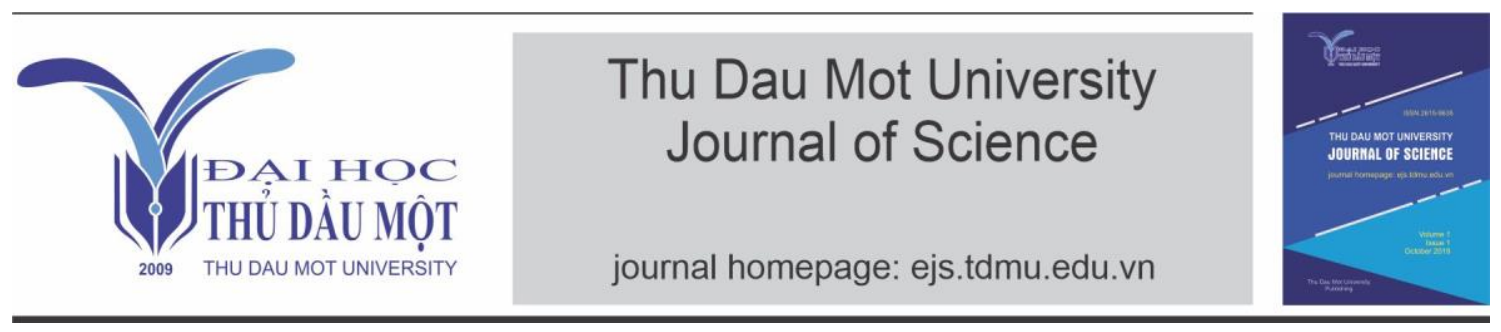

\title{
Research Factors affect the consumption of men's grooming products in Vietnam
}

by Le Huu Khanh, Mai Doan Kim Yen (National Formosa University, Taiwan)

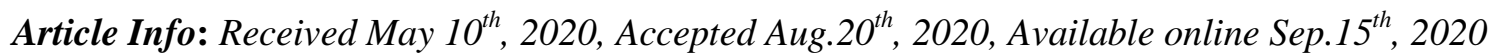
Corresponding author:lehuukhanh95@gmail.com

https://doi.org/10.37550/tdmu.EJS/2020.03.064

\begin{abstract}
Men's grooming products are very diverse and plentiful in the world today. In recent years, Vietnamese men have approached beauty trend, the old conception of beauty is also gradually changing. The demand for male beauty in Vietnam in recent years indicates that men's awareness of beauty products. The potential for grooming products for men in Vietnam is huge, but in-depth studies on this topic are limited. It is important to have specific studies analyzing the consumption of grooming products for men in Vietnam, contributing to promoting the potential of these products for business benefits. The study collected data from 458 respondents are male, analyzed the factors affecting consumer attitudes, thereby opening a specific view on men's grooming consumption in Vietnam.
\end{abstract}

Keywords: Grooming products for men, Regression, SPSS, STASTISTICA 10

\section{Introduction}

\section{Research basis}

Based on the definition of Cambridge Dictionary, grooming products are the items that people will use it to apply on their faces and bodies with the aim to upgrade the 
appearance. Nowadays, men are more aware of their appearance, strengthen health and maintain the youthfulness. In recent decades, the category of grooming products is also increasingly diverse and mutant including skincare, hair, mask, sunscreen, makeup products ... The rapid and widespread development of men's grooming products has made many companies want to invade this lucrative pie. Many companies also research and produce a variety of grooming products for men with good quality and popularity

\section{Beauty industry in Asia}

For a long time, men in Western countries have been conscious of taking care of themselves with grooming products. For Asian men, recently they also want to have good smell, beautiful and healthy skin, even men want to make up ... especially in Japan and South Korea. Music stars have a great influence on the perception of beauty and self-care for men in their own countries and other countries. The spread of J-POP and K-POP boys makes many men want to be like them, these images become a phenomenon and gradually the grooming products are indispensable products for men. As a result, the need of using grooming products has been constantly growing in Vietnam, more and more customers need to buy those products, becoming a new niche for businesses.

\section{The development of grooming products in Vietnam}

Vietnam is considered as a potential market for the development and consumption of grooming products. In the past, grooming products were only intended for use by women. Many years ago, Vietnamese men had to use shampoos, soap, lotions, face cleanser ... with women without specialized products for them (Euromonitor, 2019). Currently, the male cosmetic market is having the presence of huge players in the cosmetics industry such as: Unilever (Ax, Vaseline, Rexona...), P\&G (Gillette), Beiersdorf AG (Nivea), ICP (X-Men, Dr.Men) and so many other small competitors.

Vietnam's cosmetics market has a turnover of about 700 million US dollars a year. According to Nielsen, the spending level of Vietnamese consumers on cosmetics is not much, about 4 USD per person per month (Euromonitor, 2019). However, Vietnam is one of the fastest growing cosmetic markets in Southeast Asia. According to the report of Vietnam's Insight handbook (Kantar Worldpanel, 2019), the largest segment of the Vietnamese market is skincare. With the average amount of spending on products increased steadily in 4 years from 2015 to 2018, of which makeup remover increased 1.5 times, moisturizing increased 1.2 times and sunscreen was 1.8 times.

In the past few years in Asia, many men have started using cosmetics and shopping for a variety of products such as concealer and moisturizer ... These products are gradually gaining popularity among male customers in major markets around the world such as 
the US and China, which creating a very potential opportunity for cosmetic companies. Market researchers at JUV Consulting have estimated the value of the global men's cosmetic market to be around $\$ 1.14$ billion in 2019. Cosmetic companies hope sales of men's cosmetics can match the market for men's skin care products. This market is predicted by Euromonitor to grow $24 \%$ to $\$ 5$ billion, over the next five years.

\section{Purpose and research objectives}

When the global male cosmetics industry boomed, researchers extensively studied male grooming products. Different studies also show different perceptions of the consumption of grooming products between men and women. However, there is not much research on men's consumption of grooming products, especially in a potential market like Vietnam. In this study, we will identify and analyze the main factors: Physical attraction, Self-image, Health care needs, Social Influence, Sale promotion and Attitude. During the research, we collected information from participants with different ages, educational backgrounds, occupations, favorite brands and incomes to have a multi-dimensional view of grooming consumption.

\section{Research structure}

The research will begin by collecting data through questionnaire from 458 Vietnamese men. All collected data will be analyzed by powerful tools SPSS and STATISTICA version 10 to assess the factors that significantly affect on the consumption of men's grooming products.

The first chapter will start by providing definitions of cosmetics, foundations, current trends and future of beauty men in Vietnam. Chapter 2 will present literature review of previous studies on men's grooming products based on the proposed model: Physical attraction, Self-image, Health care needs, Social Influence, Sale promotion and Attitude. Chapter 3 is based on the distribution of the Questionnaire, the selection of survey participants and the analysis of collected data to evaluate proposed model. Chapter 4 will show the results obtained after the analysis of the data, thereby infer the summary, discussion and limitation.

\section{Literature Review}

The industry of manufacturing grooming products is growing, previous studies almost aimed at female consumers, while in the real market today in Vietnam, there are a lot of specialized grooming products for men and the market segment is on the rise. The lack of research on this new market segment has motivated the authors to study and deepen 
the grooming products for men in Vietnam. Previous studies that have mentioned grooming products for men have also contributed to addressing factors that influence consumer behavior. This study will synthesize knowledge from reliable studies to show hypotheses that fit the context in Vietnam.

\section{Physical attraction}

After puberty, men and women gradually show clear signs of different gender trends (Pathan, 2011). People are attracted to the appearance of their opponent's skin, hairstyle, scent ... making people always try to improve their appearance to attract others (Reis et al., 1982). Moreover, men also have a need for beauty, the need to improve their appearance (Sprecher,2002). Therefore, the first hypothesis is:

H1: Physical has a positive influence on men's Attitude about male grooming products

\section{Self-image}

Self-image is a conceptualization people establish in mind about what kind of person they want to be. The image of the human person also arises due to our own reactions, our specific interpretations of events, and especially the way people judge themselves as interactions with others (Frederick, 2016). Moreover, the need for male beauty has appeared and developed, grooming products are gradually becoming indispensable items for many men, especially the one who has high self-esteem (Baumeister, Campbell, Krueger, \& Voh, 2003). Accordingly, the following hypothesis was created:

H2: Self-image positively influences on the Attitude of men's grooming product consumption.

\section{Health care need}

An increasingly developed society, health care attention is also an extremely important issue not only for women but also for men (Young, 1979). We can mention a few functions from grooming products such as skincare products help men have good skins, minimize pimples, melasma, freckles; sunscreen helps them avoid skin cancer; body hygiene products help them avoid dermatological diseases ...The reason for using grooming product of men is not only to look after their appearance, men also use grooming products for medical purposes (Nyadzayo et al., 2016).

H3: Health care need have a positive influence on men's Attitude towards grooming products 


\section{Social Influence}

With the era of 4.0, the mass media has promoted products effectively and attractively. The brand also organizes many game shows, sponsors many activities, participates in advertising to attract consumers. Today, media channels are widely used for communication, education, entertainment, promotion and lifestyle, more specifically having a large presence in ads made by Key Opinion Leader - KOL (Whitler, 2014). Moreover, with the development and learning of advanced things from abroad in Vietnam, people have a more open-minded view, it is not regulated that only women have the need to use grooming products (Parsa et al., 2015).

H4: Social Influence positively impacts the Attitude of men about grooming product consumption in Vietnam.

\section{Sales promotion}

The promotions are organized to stimulate customers' demand for products. The company also organizes sale activities, use free sample activities or give some gifts for participants. When customers try the product and achieve their satisfactions, they will have a good impression of the item and want to continue using it (Blackwell et al., 2001). Discounts in stores, or giving customers with other gifts will also impress customers on the product (Taylor, 2012).

H5: Sales promotion positively affects Attitude of men's grooming product consumption.

\section{Attitude}

Attitude is known to be one of the main factor influences on product consumptions, some studies showed that companies could predict consumption based on customer attitudes to products (Chan and Lau, 2002). In this research, all factors: Physical attraction, Self-image, Health care needs, Social Influence, Sale promotion simultaneously influence on customer attitude to grooming products. Men's attitude towards cosmetic products will stimulate buying behavior of grooming products (Wang and Horng, 2016).

H6: Attitude positively affects on male grooming products consumption in Vietnam 
Le Huu Khanh, Mai Doan Kim Yen- Volume 2 - Issue 3-2020, p. 267-279.

\section{Research methodology}

\subsection{Collect data and questionnaire}

The study collected data from 458 respondents who were male in Vietnam. In addition to a multi-dimensional view of customers of grooming products in Vietnam, the research paper also collected their information: Age, Marital Status, Highest education level, Occupation, Monthly income, Favorite brands.

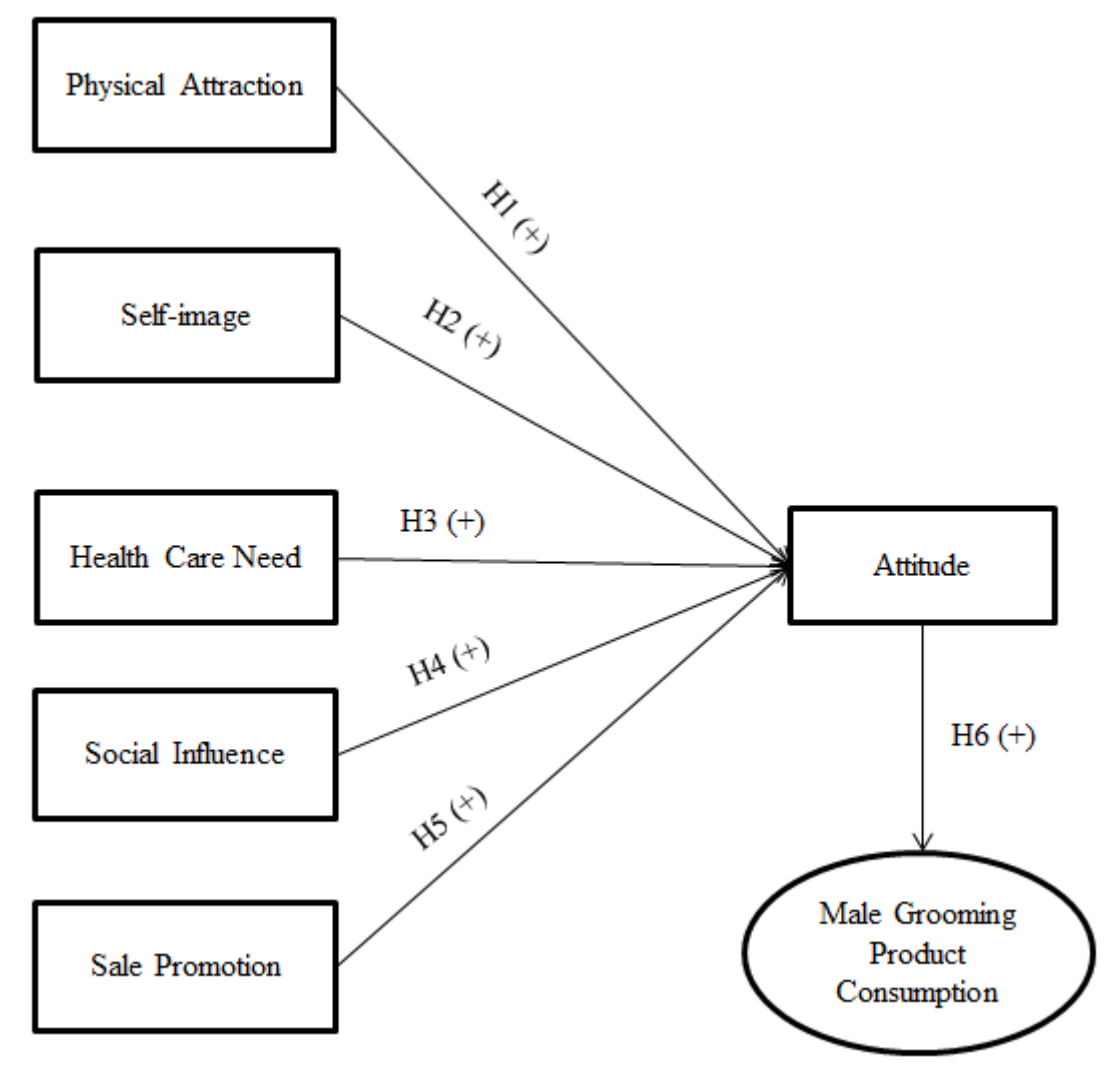

Figure 1. Proposed Model

\section{Data analysis}

Exploratory Factor (EFA): Exploratory Factor (EFA) is a tool mainly used to shrink and summarize data. This research paper will use Rotated Component Matrix and KMO to assess the adequacy of the samples collected in the study.

Confirmatory factor analysis (CFA): Confirmatory factor analysis (CFA) is a powerful tool used to analyze the immutable quality of image perspectives that will control their inactive elements. 
Regression analysis: Through the results of Beta and $\mathrm{T}$ value, it is possible to run from the collected results to find out which factors are Supported and Rejected. Regression analysis is also an important step to test how the factors in the proposed model.

\section{Descriptive Statistics}

STATISTICA 10 is applied in this investigation because of the decent variety of statistic information accumulation in age, marital status, highest education level, occupation, monthly income, favorite brands. Descriptive Statistic is characterized as the pointer that portrays and encourages the quantitative information into the synopsis structure.

\section{Results}

\section{Demographic statistics}

This research distributed 458 questionnaires to Vietnamese men and 100\% of samples received. Table 4.1 presents the demographic information of respondents.

The number of respondents with the largest number is from 19 to 25 years old: 199 people (43.4\%). Regarding marital status, the number of single men participating in the questionnaire was higher than the number of married people with 292 respondents (63.8\%). The education of the participants is mainly men with Bachelor Degree (220 people, $48.0 \%$ ). The occupation of the survey participants of this study is mostly Company-employee (228 people, 49.8\%), monthly income from USD \$500 - USD \$1000 reached the highest percentage (211 respondents, 46.1\%). Beiersdorf AG was selected by respondents was the most favorite brand in this study with 123 people (26.9\%).

TABLE 1. Demographic statistics

\begin{tabular}{|l|l|c|c|}
\hline \multicolumn{2}{|l|}{ Category } & Frequency & Percent (\%) \\
\hline \multirow{4}{*}{ Age } & Under 19 & 35 & 7.6 \\
\cline { 2 - 4 } & $19-25$ & 199 & 43.4 \\
\cline { 2 - 4 } & $26-35$ & 145 & 31.7 \\
\cline { 2 - 4 } & $36-45$ & 60 & 13.1 \\
\cline { 2 - 4 } & Over 45 & 19 & 4.1 \\
\cline { 2 - 4 } & Total & 458 & 100 \\
\hline \multirow{4}{*}{ Marital Status } & Single & 292 & 63.8 \\
\cline { 2 - 4 } & Married & 166 & 36.2 \\
\cline { 2 - 4 } & Total & 458 & 100 \\
\hline Highest education level & Bachelor & 220 & 48.0 \\
\hline
\end{tabular}


Le Huu Khanh, Mai Doan Kim Yen- Volume 2 - Issue 3-2020, p. 267-279.

\begin{tabular}{|c|c|c|c|}
\hline & Master & 145 & 31.7 \\
\hline & Doctor & 34 & 7.4 \\
\hline & Other & 59 & 12.9 \\
\hline & Total & 458 & 100 \\
\hline & Student & 145 & 31.7 \\
\hline & Self- Business & 72 & 15.7 \\
\hline Occupation & Company-employee & 228 & 49.8 \\
\hline & Other & 13 & 2.8 \\
\hline & Total & 458 & 100 \\
\hline & Less than $\$ 500$ USD & 167 & 36.5 \\
\hline Mont in & USD $\$ 500$ - USD $\$ 1000$ & 211 & 46.1 \\
\hline 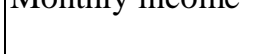 & More than USD $\$ 1000$ & 80 & 17.5 \\
\hline & Total & 458 & 100 \\
\hline & Unilever & 84 & 18.3 \\
\hline & ICP & 70 & 15.3 \\
\hline Foyorit hrondl & $P \& G$ & 112 & 24.5 \\
\hline ravonte oranus & Beiersdorf AG & 123 & 26.9 \\
\hline & Others & 69 & 15.1 \\
\hline & Total & 458 & 100 \\
\hline
\end{tabular}

\section{EFA and CFA evaluation}

The sample is adequate if the value of KMO test is greater than 0.5 (Field, 2000; Kaiser, 1974). In this study, KMO reached a value of 0.766, surpassing the standard value, reflected the adequate sample size in this research in EFA procedure.

TABLE 2. Rotation Sums of Squared Loadings results

\begin{tabular}{|c|c|c|}
\hline Total & \% of Variance & Cumulative \% \\
\hline 2.913 & 15.331 & 15.331 \\
2.151 & 11.323 & 26.655 \\
2.115 & 11.132 & 37.786 \\
2.062 & 10.854 & 48.64 \\
1.778 & 9.359 & 57.999 \\
\hline
\end{tabular}

In this study, five independent variables are predicted that have influence on the attitude of buying men's grooming products in Vietnam, so in the table Rotation Sums of Squared Loadings results only has five factors are rotated. Cumulative value indicates 
Total Variance Explained reached 57,999\%, met the standard (greater than 50\%). From that result, $57.999 \%$ of the change in factors explained by the observed variables.

After running Cronbach's alpha, all items have factor loading over the recommended number of 0.3 , which means all factors are satisfactory. Besides, for reliability, greater than 0.6 as the minimum value for Cronbach's alpha (Nunnally, 1978).

TABLE 3. Rotated Component Matrix

\begin{tabular}{|c|c|c|c|c|c|}
\hline & \multicolumn{5}{|c|}{ Component } \\
\hline & 1 & 2 & 3 & 4 & 5 \\
\hline PA4 & 0.821 & & & & \\
\hline PA1 & 0.773 & & & & \\
\hline PA3 & 0.701 & & & & \\
\hline PA5 & 0.648 & & & & \\
\hline PA2 & 0.607 & & & & \\
\hline S4 & & 0.755 & & & \\
\hline S1 & & 0.718 & & & \\
\hline S2 & & 0.683 & & & \\
\hline S3 & & 0.614 & & & \\
\hline SI2 & & & 0.725 & & \\
\hline SI3 & & & 0.725 & & \\
\hline SI1 & & & 0.555 & & \\
\hline SP1 & & & & 0.738 & \\
\hline SP2 & & & & 0.685 & \\
\hline SP3 & & & & 0.617 & \\
\hline SP4 & & & 0.402 & 0.430 & \\
\hline HCN3 & & & & & 0.775 \\
\hline $\mathrm{HCN} 2$ & & & & & 0.741 \\
\hline HCN1 & & & & & 0.704 \\
\hline
\end{tabular}

TABLE 4. CFA results and loadings

\begin{tabular}{|c|c|c|c|c|c|}
\hline \multicolumn{2}{|c|}{ Constructs Items } & Cronbach's alpha & \multicolumn{2}{|c|}{ Constructs Items } & Cronbach's alpha \\
\hline \multicolumn{2}{|c|}{ Physical Attraction } & 0.789 & \multicolumn{2}{|c|}{ Social Influence } & 0.666 \\
\hline PA1 & 0.607 & 0.737 & S1 & 0.493 & 0.566 \\
\hline PA2 & 0.489 & 0.773 & S2 & 0.465 & 0.588 \\
\hline PA3 & 0.566 & 0.75 & S3 & 0.359 & 0.654 \\
\hline PA4 & 0.649 & 0.725 & S4 & 0.473 & 0.581 \\
\hline PA5 & 0.54 & 0.761 & & & \\
\hline \multicolumn{2}{|c|}{ Self-image } & 0.699 & \multicolumn{2}{|c|}{ Sale Promotion } & 0.635 \\
\hline SI1 & 0.464 & 0.671 & $\mathrm{P} 1$ & 0.369 & 0.603 \\
\hline SI2 & 0.589 & 0.513 & $\mathrm{P} 2$ & 0.423 & 0.562 \\
\hline
\end{tabular}


Le Huu Khanh, Mai Doan Kim Yen- Volume 2 - Issue 3-2020, p. 267-279.

\begin{tabular}{|c|c|c|c|c|c|}
\hline \multirow[t]{2}{*}{ SI3 } & \multirow[t]{2}{*}{0.495} & \multirow[t]{2}{*}{0.632} & P3 & 0.494 & 0.513 \\
\hline & & & $\mathrm{P} 4$ & 0.388 & 0.586 \\
\hline \multicolumn{2}{|c|}{ Health Care Need } & 0.633 & \multicolumn{2}{|c|}{ Attitude } & 0.695 \\
\hline $\mathrm{HC} 1$ & 0.415 & 0.572 & A1 & 0.456 & 0.671 \\
\hline $\mathrm{HC} 2$ & 0.467 & 0.503 & A 2 & 0.576 & 0.519 \\
\hline $\mathrm{HC} 3$ & 0.448 & 0.529 & A3 & 0.502 & 0.613 \\
\hline
\end{tabular}

\begin{tabular}{|l|l|l|}
\hline \multicolumn{2}{|l|}{ Constructs Items } & Cronbach's alpha \\
\hline Male Grooming Product Consumption & 0.8 \\
\hline C1 & 0.556 & 0.777 \\
\hline C2 & 0.627 & 0.743 \\
\hline C3 & 0.733 & 0.686 \\
\hline C4 & 0.55 & 0.784 \\
\hline
\end{tabular}

About Rotated Component Matrix, item with rotated factor loading are greater than 0.5 will be retained. Any factor with the value of 0.4 or greater will be excluded from the analysis. Rotated Component Matrix has shown five independent variables: PA (Physical Attraction): PA1, PA2, PA3, PA4, PA5; S (Self-image): S1, S2, S3, S4; SI (Social Influence): SI1, SI2, SI3; SP (Sale Promotion): SP1, SP2, SP3 (SP4 is eliminated); HCN (Health Care Need): HCN1, HCN2.

\section{Regression analysis}

As a standard, if the $\mathrm{P}$ value is $<0.05$, the experimental results are considered statistically significant, hence, we can reject the null hypotheses, and accept the alternative hypotheses. The regression equation:

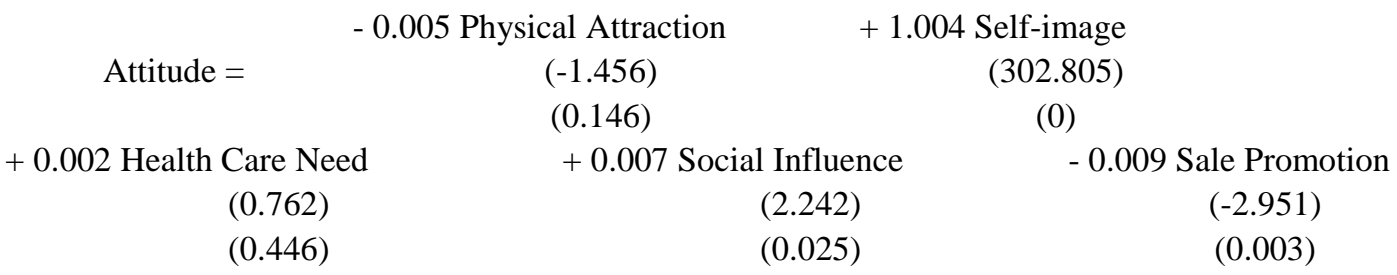

Based on the results of the independent variables, the following factors have a positive effect on Attitude: Self-image ( $\mathrm{B}=1.004, \mathrm{P}=0.000)$, Social Influence $(\mathrm{B}=0.007, \mathrm{P}=0.025)$, Sale Promotion $(\mathrm{B}=-0.009, \mathrm{P}=0.003)$. Attitude factor after analysis also results in a positive impact on Male Grooming Product Consumption in Vietnam ( $\mathrm{B}=0.467, \mathrm{P}=0.000)$. 
TABLE 5. Regression Model

\begin{tabular}{|l|c|c|c|}
\hline \multicolumn{1}{|c|}{ Model } & Beta & T value & P value \\
\hline (Constant) & 0 & 1.859 & 0.064 \\
\hline Physical Attraction & -0.005 & -1.456 & 0.146 \\
\hline Self-image & 1.004 & 302.805 & 0 \\
\hline Health Care Need & 0.002 & 0.762 & 0.446 \\
\hline Social Influence & 0.007 & 2.242 & 0.025 \\
\hline Sale Promotion & -0.009 & -2.951 & 0.003 \\
\hline Attitude & 0.467 & 11.281 & 0 \\
\hline
\end{tabular}

TABLE 6. Results of Regression

\begin{tabular}{|l|l|c|c|c|}
\hline \multicolumn{1}{|c|}{ Hypothesis } & Coefficient & P-value & Results \\
\hline H1 & Physical Attraction $\rightarrow$ Attitude & -0.005 & 0.146 & Rejected \\
\hline H2 & Self-image $\rightarrow$ Attitude & 1.004 & 0.000 & Supported \\
\hline H3 & Health Care Need $\rightarrow$ Attitude & 0.002 & 0.446 & Rejected \\
\hline H4 & Social Influence $\rightarrow$ Attitude & 0.007 & 0.025 & Supported \\
\hline H5 & Sale Promotion $\rightarrow$ Attitude & -0.009 & 0.003 & Supported \\
\hline H6 & $\begin{array}{l}\text { Attitude } \rightarrow \text { Male Grooming Product } \\
\text { Consumption }\end{array}$ & 0.467 & 0.000 & Supported \\
\hline
\end{tabular}

\section{Discussion and Conclusion}

\section{Discussion of results}

H1: Physical attraction positively affects the use of the Attitude of men's grooming product consumption. The results obtained from the data of the respondents gave the results Rejected. The results have been against the argument that using cosmetics can make people, both men and women, more attractive, leading to grooming purchases (Graham and Jouhar, 1980). In Vietnam, grooming products do not completely change the appearance of men, and that is not the main purpose to use grooming products. Moreover, to upgrade the appearance, there are many other factors such as clothing, hairstyles, shoes ... and grooming products currently not a major solution for men in Vietnam to increase physical attraction.

H2: Self-image after Regression analysis, this factor shows positively impacts on the Attitude of men's grooming product consumption, agreed with Cheng and 
Le Huu Khanh, Mai Doan Kim Yen-Volume 2 - Issue 3-2020, p. 267-279.

Ting's previous opinion (2010). Grooming products can speak of men's preferences, personalities, social-position... in Vietnam.

H3: Hypothesis Health Care Need has a positive impact on the attitude of grooming products in Vietnam was Rejected. Although grooming products do actually work in terms of health care, it is not a big factor in making men buy these products in Vietnam.

H4: Social Influence positively impacts on the Attitude of men's grooming product consumption in Vietnam is Supported. In the era of 4.0, communication tools is very powerful and effectively exploited by businesses. Men also want their own grooming products, not the same product as women. Social influence also stimulates the need to use grooming products for each item in accordance with the preferences, with the body characteristics of male.

H5: Sale Promotion based on the analysis result (Supported) shows a positive impact on the attitude of grooming products in Vietnam. Reasonable prices, promotional gifts, and the value they receive when using the product make men look positively on their intention to buy grooming products (Feng, 2008).

H6: Attitude positively affects the consumption of grooming products in Vietnam. When customers have a good attitude, the probability of buying their products is very high (Chan and Lau, 2002).

\section{Limitations and Further research}

Although there have been efforts in the research process, the research also has some unavoidable limitations. The number of people interviewed is still not very large, if the number was increased with a large-scale survey, the study could discover new knowledge about grooming products for men in Vietnam. Questionnaire collection is the process of collecting data online, if combined with direct questionnaire distribution, respondents will probably better understand the questionnaire they are received.

The following study will try to expand the scope of the survey to gain a more in-depth look at men's grooming product consumption. The following studies will try to discover more reasons why men want to use grooming products, contributing to the proposed model to be more complete.

\section{References}

Baumeister, R.F., Campbell, J.D., Krueger, J.I. and Vohs, K.D. (2003). Does high self-esteem cause better performance, interpersonal success, happiness, or healthier lifestyles? Psychological Science in the public interest, 4(1), 1-44 
Chan, R. Y., and Lau, L. B. (2002). Explaining Green Purchasing Behavior: A Cross-Cultural Study on American and Chinese Consumers. Journal of International Consumer Marketing, 14, 9-40

Cheng, F. S., Ooi, C. S., \& Ting, D. H. (2010). Factors affecting consumption behavior of metrosexual toward male grooming products. International Review of Business Research Papers, 6(1), $574-590$

Euromonitor International (2019). Country Report Men's Grooming in Vietnam

Feng, W. (2008). Male cosmetics advertisements in Chinese and U.S. Men's Lifestyle Magazine (Diss.). Ohio University, Athens, $\mathrm{OH}$

Graham, J.A., \&Jorhar, J.A. (1980). Cosmetics considered in the context of physical attractiveness; A review. International Journal of Cosmetic Science, 2, 77-101

Kaiser, H. F. (1974). An index of factorial simplicity. Psychometrika, 39, 31-36

Kantar Worldpanel (2019). Vietnam's Insight handbook

Kantar Worldpanel. (2019). Beauty Trends in Asia report

Nunnally, J. C. (1978). Psychometric theory (2nd ed.). New York: McGraw-Hill

Nyadzayo, M., Leckie, C., McDonald, H. (2016). CSR, relationship quality, loyalty and psychological connection in sports. Marketing Intelligence and Planning, 34 (6), 883-898

Parsa, H.G., Lord, K.R., Putrevu, S., Kreeger, J. (2015). Corporate social and environmental responsibility in services: will consumers pay for it? Journal of Retailing and Consumer Services, 22, 250-260

Pathan, S.S. (2011). Adolescent's attitude towards the opposite-sex. Journal of Arts Science \& Commerce, 2(4), 192-199.

Reis, H.T., Wheeler, L., Spiegel N. \&Kernis, H.M. (1982). Physical Attractiveness in Social Interaction: II. Why Does Appearance Affect Social Experience? Journal of Personality and Social Psychology, 43(5), 979-996

Sprecher, S. (2002). Sexual satisfaction in premarital relationships: Associations with satisfaction, love, commitment, and stability. Journal of Sex Research, 39, 190-196

Sprecher, S. (2002). Sexual satisfaction in premarital relationships: Associations with satisfaction, love, commitment, and stability. Journal of Sex Research, 39, 190-196

Taylor, C.R. (2012). Back to the future : some topics we should not forget about in advertising research. International journal of Advertising, 30(4), 699-700.

Wang, H.J., Horng, S.C. (2016). Exploring green brand associations through a network analysis approach. Psychology and Marketing, 33(1), 30-35.

Young, J.W. (1979). Symptom disclosure to male and female physicians: Eff ects of sex,physical attractiveness and symptom type. Journal of Behavioural Medicine, 2, 159-169. 